\title{
ТЕРРИТОРИАЛЬНЫЙ СОСТАВ ФЕДЕРАТИВНОГО ГОСУДАРСТВА: ПРИНЦИПЫ ФОРМИРОВАНИЯ И КОНСТИТУЦИОННОЕ ЗАКРЕПЛЕНИЕ
}

\begin{abstract}
Аннотация: Предметом данного исследования является историко-правовой опыт формирования территориального и субъектного состава федеративных государств мира и соответствующий комплекс конституцчионных норм, закрепленных в текстах федеральных конституциий. Изучению подверглись конституцчи, более пятидесяти федеративных государств, принятые в момент создания федерации. В статье анализируются способы конституционного закрепления субъектного состава федерации, принцииы формирования территории субъектов федерации, порядок изменения грании между ними, принципь формирования федеральных территорий и столичных округов в составе федерации. В рамках целостно-системного подхода, диалектики и на основе принципа историзма были использованы сравнительно-правовой метод и метод формально-юридического анализа. Выводы: Отсутствие нормативного закрепления субъектного состава федерации в тексте федеральной конституции является пробелом, который необходимо восполнить; однако не следует делать однозначного вывода об отсутствии федеративного начала в организации публичной власти: для этого нужно проанализировать весь комплекс конституционных норм. Наиболее стабильными стали те федерации, конституциии которых изначально содержали полный перечень фактически вошедших в состав субъектов федерации, предусматривали условия для вхождения новых субъектов, закрепляли порядок пересмотра грании между субъектами федерации. Следует признать положительным опыт тех федераций, формирование территории которых осуществлялось, исходя из принципа экономической самодостаточности каждого субъекта федерации, где в основу формирования территории был положен территориальный принции, и где с учетом географических и климатических условий часть территории федерации оставалась под прямым управлением федеральных властей, не переходя в состав территории какого-либо субъекта федерации, и не создавая асимметрии его правового статуса.
\end{abstract}

Ключевые слова: Конституция, федерация, федерализация, территория, государство, constitution, federation, federalization, territory, state.

Abstract: The subject of this research is the historical legal experience of the formation of the territorial and constituent composition of the federative states of the world and the corresponding complex of constitutional norms established in the text of federal constitutions. The study is conducted on the constitutions of over 50 federative states signed at the time of the creation of federation. This work presents the analysis on the means of constitutional establishment of the constituent composition of a federation, principles of formation of the territory of the subjects of the federation, order of changes to the borders between them, as well as the principles of formation of federal territories and capital districts in the composition of the federation. The author concludes that the lack of normative establishment of the constituent composition of a federation in the text of the federal constitution is a gap that needs to be filled, but not unambiguous conclusion should be made on the absence of federal foundation in the organization of public authority: this will require analysis of the entire complex of the constitutional norms.

Keywords: State, territory, federalization, federation, constitution, constituent member, Russian Federation, Federal subject, Borders, Legal status.

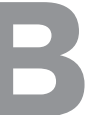

соответствии с классическим определением государства в юридической науке территория является одним из существенных признаков государства. При федеративной форме государственного устройства вопрос о составе территории приобретает особое значение и может стать краеугольным камнем существования самого государства, так как способен породить комплекс проблем политического, экономического и социального характера. Поэтому территориальный состав федеративного государства целесообразно закрепить в федеральной конституции непосредственно в момент ее принятия, предусмотрев конституционные основания и процедуры дальнейших территориальных изменений.

При принятии первых федеральных Конституций почти в каждой из них фиксировал- 
ся состав нового союза. Он мог предусматривать наличие как субъектов федерации, так и территориальных образований, имеющих особый правовой статус - федеральных территорий или столичных (федеральных) округов. Состав федерации, наименования и названия ее составных частей в тексте конституции могли быть указаны:

- в специальной статье (ст. 2 Конституции Танзании 1956 г. ${ }^{1}$, ст. 65 Конституции России 1993 г. ${ }^{2}$ );

- в статье, закрепляющей численность депутатов пропорционально избираемой верхней или нижней палаты парламента (статья I Конституции Соединенных Штатов Америки 1787 г. $^{3}$, ст. 38 Конституции Аргентины 1859 г. ${ }^{4}$ );

- в некоторых конституциях территориальный состав федерации закреплялся в положениях преамбулы, которые в принципе не являлись нормативными, с последующим дублированием в тексте конституционного Акта (преамбула, ст. 22 и ст. 37 Акта о Британской Северной Америке 1867 г.5);

- в заключительных и переходных положениях (Конституция Федеративных Штатов Микронезии ${ }^{6}$ )

- в приложении к конституции (Конституция Республики Индия ${ }^{7}$ ).

Парадоксально, но в ряде конституций, учреждавших федеративную форму государственного устройства, перечня субъектов федерации закреплен не был. Так, например, Конституция России 1918 г. содержала следующую норму: «Российская Советская Республика учреждается на основе свободного союза свободных наций как федерация Советских национальных республик» ${ }^{8}$. Из этого следовало, что

\footnotetext{
${ }^{1}$ Временная Конституция Танзании 1965 г. // Конституции государств Африки. Т. 2. М., 1966. С. 494-548.

${ }^{2}$ Конституция Российской Федерации. М. : Юридическая литература, 1993.

${ }^{3}$ Конституция Соединенных Штатов Америки 1787 г. / Конституции и законодательные акты буржуазных государств XVII-XIX вв.: Сборник документов / Под ред. проф. П. Н. Галанзы. М.: Гос. изд-во юрид. лит., 1957. С. 178-190

${ }^{4}$ Конституция Аргентинской нации от 1 мая 1853 г. / Конституции государств американского континента: в 2 т. Т. 1. Перевод под ред. проф. Г. С. Гурвича. М. : Изд-во иностр. лит-ры, 1957. C. 12-37.

${ }^{5}$ Акт о Британской Северной Америке 1867 г. / Конституции государств американского континента: в 2 т. Т. 2. Перевод под ред. проф. Г. С. Гурвича. М.: Изд-во иностранной лит-ры, 1959. C. $13-50$.

${ }^{6}$ Конституция Федеративных Штатов Микронезии 1979 г. [Electronic resource] // URL : http://www.paclii.org/fm/legis/consol_act/ cotfsom468 (13.05.2014).

${ }^{7}$ Приложение первое к Конституции Индии //

${ }^{8}$ Конституция (Основной закон) РСФСР от 10 июля 1918 г. / Собрание узаконений РСФСР. 1918. № 51. Ст. 582. Ст. 2.
}

учреждаемый федерализм был скорее фиктивен, чем реален; именно к такому выводу можно прийти в результате комплексного анализа текста названной Конституции и помня исторические судьбы советского федерализма.

Конституция Папуа Новой Гвинеи также не называла состав федерации, указывая лишь, что состав провинций должен быть закреплен органическим законом ${ }^{9}$, однако сомнения в федеративном характере этого государства рассеивают статьи, содержащиеся в части VI A, предусматривающие учреждение органов государственной власти провинций, в том числе законодательных, а также нормы, обязывающие провинции принять свои конституции.

По нашему мнению, отсутствие нормативного закрепления субъектного состава федерации в тексте федеральной конституции, безусловно, является пробелом в законодательстве, который необходимо восполнить. Однако в данном случае не следует делать однозначного вывода об отсутствии федеративного начала в организации публичной власти: для этого нужно проанализировать весь комплекс конституционных норм.

Субъектный состав федерации может складываться из однородных единиц: штатов (Соединенные Штаты Америки, Соединенные Штаты Мексики, Содружество Австралия), провинций (Канада, Бразилия, Аргентина), федеральных земель (Федеративная Республика Германия, Австрия), эмиратов (Объединенные Арабские Эмираты). Подобный способ закрепления субъектного состава свидетельствует о симметрии статусов субъектов федерации, если не реальной, то хотя бы потенциальной. Напротив, если конституция предусматривает несколько видов субъектов в составе федерации, то их правовое положение, скорее всего, имеет те или иные нюансы, а, следовательно, сама федерация является асимметричной со всеми вытекающими из этого проблемами.

Примерами федераций, в момент основания которых закреплялся состав неоднородных субъектов, являются: Швейцария (кантоны и полукантоны ${ }^{10}$ ), Индия (изначально конституция определяла несколько категорий штатов с разным правовым статусом - штаты категорий А, В и С), Малайзия (штаты, княжества и сеттльменты ${ }^{11}$ ), современная Россия

\footnotetext{
${ }^{9}$ Ст. 5 Конституции Папуа Новой Гвинеи 1975 г. [Electronic resource] // URL: legis/consol_act/cotisopng534 (17.02.2014).

10 Федеральная Конституция Швейцарии 1848 г. / пер. с нем. С. А. Соломоновой // Правоведение. 2005. № 3. С. 167-183.

${ }^{11}$ Ст. 1 Конституции Малайской Федерации / Конституции государств Юго-Восточной Азии Тихого океана. М., 1960. С. 245-396.
} 
(несмотря на результаты процесса объединения до сих пор остается шесть видов субъектов федерации - республики, края, области, города федерального значения, автономная область и автономные округа ${ }^{12}$ ).

Самая сложная модель федерации предусмотрена федеральной Конституцией Бельгии, которая в плане субъектного состава является «двойной федерацией», одновременно состоящей из трех лингвистических сообществ и трех территориальных регионов ${ }^{13}$. Данная структура сложилась исторически и в настоящее время реформирована или изменена быть не может в силу остроты политических и социальных противоречий внутри федерации.

Следует отметить, что Индия и Малайзия со временем смогли реформировать субъектный состав своих федераций и пришли к однородности их наименований (штаты Индии и штаты Малайзии), и, следовательно, находятся на пути к юридическому выравниваю их конституционных статусов внутри федерации, что в целом следует рассматривать как оптимизацию федеративных отношений.

Практика создания в ряде федераций федеральных территорий и столичных округов, с нашей точки зрения, является оправданной, так как управление такими составными территориальными частями федерации предусматривает существенные особенности.

Федеральные территории формируются в основном в малозаселенных или труднодоступных местах, на территориях с суровыми климатическими условиями, т. е. там, где необходима существенная финансовая и ресурсная поддержка со стороны федерального центра, а, следовательно, нет смысла создавать дублирующий уровень органов государственной власти, который будет заведомо неэффективен или вообще не нужен (в арктических пустынях Канады, на островах Индии, Аргентины и Венесуэлы).

Столичные же округа (иногда они именуются федеральными, например, федеральный округ Колумбия в Соединенных Штатах Америки), напротив, обладают избыточными для субъекта федерации ресурсами и, кроме того, осуществляют функции столицы; следовательно, разумно подчинить их непосредственно федеральной власти, а не создавать на их территории одновременно двухуровневую систему органов и федеральной государственной власти, и государственной власти субъекта федерации, что само по себе является неэффективным хотя бы с точки зрения бюджетных расходов на содержание аппарата

\footnotetext{
${ }^{12}$ Ст. 65 Конституции России 1993 г.

${ }^{13}$ Ст. 1-5 Конституции Королевства Бельгия 1994 г. / Конституции государств Европы: В 3 т. Т. 1 / Под общ. ред. Л. А. Окунькова. М.: Изд-во НОРМА, 2001. С. 341-380.
}

чиновников. Некоторые федеральные конституции изначально предусматривали создание столичных округов (Аргентина, Австралия), в некоторые были внесены соответствующие изменения в процессе развития федеративных отношений (Соединенные Штаты Америки).

Вопрос о создании федеральной столичной территории иногда приобретал политическую остроту. Так, например, Конституция Австралии закрепила норму, устанавливающую, что штаты вправе передавать союзу какие-либо территории, и что столичная «территория должна находиться в штате Новый Южный Уэльс на расстоянии не менее ста миль от Сиднея» 14. Такая скрупулезная регламентация объясняется наличием спора между двумя самыми мощными штатами Австралии, претендовавшими на лидерство в Союзе - Новым Южным Уэльсом и Викторией за право контролировать федеральные доходы и влиять на федеральную политику. В результате этого спора был достигнут компромисс, и столицу решено было основать заново на специально выделенной территории между двумя крупнейшими городами Австралии - Мельбурном и Сиднеем. Примерно за тридцать лет до этого также путем компромисса был решен спор о нахождении столицы Канады. И, хотя территории со специальным статусом для нее выделено не было, выбранный лесопильный поселок - Оттава - находился примерно посередине между Монреалем и Квебеком.

В. Е. Чиркин считает, что теоретически составными частями собственно федерации являются лишь ее субъекты - ведь именно они создавали Союз, предусматривая для себя идентичное правовое положение $^{15}$. При институционализации федеральных территорий в составе федерации возникает определенное правовое противоречие: не-субъекты являются составными частями федеративного государства, но не представляют собой конституирующих элементов собственно федерации.

Данное противоречие может быть объяснено исторически или географически: например, федеральные территории Канады были сформированы в малозаселенных и экономически неразвитых землях, находившихся к северу от так называемого «Плодородного пояса», в пределах которого всегда предпочитали селиться жители Британской Северной Америки; труднодоступные, удаленные

\footnotetext{
${ }^{14}$ Ст. 125 Конституционного Акта Содружества Австралия от 9 июля 1900 г. / Конституции государств Юго-Восточной Азии и Тихого океана. Перевод под ред. 3. И. Луковниковой. М. : Изд-во иностранной лит-ры, 1960. С. 16-52.

15 Чиркин В.Е. Современное федеративное государство. М., 1997. C. $28-33$
} 
острова, например, в составе Индии, или Венесуэлы, также не обладают ресурсами, достаточными для статуса субъекта федерации. Разрешается же оно правовыми средствами: федеральные (в Индии союзные) территории имеют ограниченное фиксированное представительство в федеральном парламенте и управляются чиновниками, назначенными из федеральной столицы. Кроме того, федеральные территории часто являются тем резервом, за счет которых при необходимости расширяются территории сопредельных субъектов федерации.

При закреплении состава федераций некоторые федеральные конституции закрепляли не фактический, а расширенный перечень субъектов федерации. Это делалось по политическим мотивам из расчета на вхождение в состав союза сопредельных территорий, которые по разным причинам пока оставались за его пределами. Это касалось, например, Конституции Федеративных Штатов Микронезии ${ }^{16}$, которая предусматривала состав федерации из семи субъектов вместо четырех, которые фактически вошли в нее по результатам референдума.

Такие нормы федеральной конституции можно расценивать как возможность расширения или реформирования состава федерации, причем если в одних случаях речь идет об абстрактных возможностях появления в союзе новых членов, то в других это звучит как осознанная и четкая цель, достижение которой рассчитано на ближайшую историческую перспективу. Так, например, канадцы еще в 1867 г. отразили в тексте конституционного Акта свое желание видеть в составе федерации провинции Ньюфаунленд, Британскую Колумбию, Остров Принца Эдуарда, а также Северо-Западные территории и Землю Руперта. Более того, для Ньюфаунленда и Острова Принца Эдуарда Актом были предусмотрены нормы представительства в Сенате ${ }^{17}$. Однако Ньюфаунленд вошел в состав Канады только в 1949 г., спустя почти восемьдесят лет после создания федерации.

Исследователь германского федерализма А. А. Ахтамзян отмечает, что «Концепция «провизориума», то есть временного учреждения федерации в составе ряда германских земель, названных в статье 23 Основного закона в редакции 1949 г,, оставляла теоретическую (юридическую) возможность вхождения или включения в состав федерации других частей Германии» ${ }^{18}$. Это уникальная история вос-

16 Ч. 6 статьи 15 Конституции Федеративных Штатов Микронезии 1979 г.

${ }^{17}$ Ст. 146 и 147 Акта о Британской Северной Америке 1867 г.

${ }^{18}$ Ахтамзян А. А. История германского федерализма от «союза князей» до конституционной федерации / Федерализм: Теория создания федерации только на части национальных земель, которая спустя около сорока лет завершилась полным объединением Германии на основе принципа федерализма.

Для первых федеральных конституций был характерен запрет формирования новых субъектов федерации за счет территории субъектов, вошедших в состав государства: конституция Аргентины прямо запрещала создание «новых провинций на территории другой или других провинций», так же как и слияние нескольких провинций. Однако в ст. 13 Конституции Аргентины присутствовала оговорка, что это возможно только с согласия законодательных органов заинтересованных субъектов федерации и федерального парламента. Подобные положения, видимо, были заимствованы из ст. IV Конституции Соединенных Штатов Америки. Такие положения, закреплялись в конституциях федеративных государств, которые имели реальную возможность расширяться территориально.

Напротив, Конституция Содружества Австралия, которое почти никогда не испытывало внешних угроз и территориальных притязаний, допускала передачу любой части территории штата союзу по предложению парламента штата и при согласии властей союза. Кроме того, глава VI названной Конституции, которая называется «Новые штаты» ${ }^{19}$, предусматривала самые разнообразные способы расширения состава федерации как за счет внутренних, еще неосвоенных центральных территорий, так и за счет приобретения внешних территориальных владений. Новый штат мог быть образован четырьмя способами:

- принятием новых штатов в состав Союза;

- предоставлением любой территории Королевой Великобритании под власть Австралийского союза и принятой им (так произошло, например, с территорией Папуа-Новая Гвинея, хотя затем здесь было создано суверенное государство);

- отделением части территории любого штата с согласия его парламента;

- объединением двух и более штатов или частей штатов с согласия их парламентов.

Кроме того, конституция предусматривала получение или приобретение территории союзом «любым иным способом», а также по соглашению между федеральным парламентом и парламентом или избирателями штата увеличить или уменьшить территорию штата или каким-либо иным способом

и история развития: сб. ст. / Отв. ред. М. Н. Марченко. - М.: Юристь, 2000. - С. 128.

${ }^{19}$ Ст. 111, 121-124 Конституции Содружества Австралии. 
изменять его границы. Таким образом, в Австралии появление нового штата практически не ограничивалось никакими запретами.

Прерогативу изъятия любой территории из состава субъекта федерации в пользу федерации предусматривает Конституция Бельгии. При этом норма формулируется предельно жестко: «закон может изъять из провинциального деления некоторые территории, границы которых он определяет, подчинить их непосредственно федеральной исполнительной власти и определить для них особый статус» ${ }^{20}$. Императивный характер данной статьи несколько смягчается условием согласия большинства представителей соответствующей лингвистической группы в каждой палате парламента при принятии такого закона.

Процедура «допущения» в союз новых субъектов федерации, как правило, предусматривала обязательное волеизъявление с одной стороны - парламентов или непосредственно населения заинтересованных территорий, стремившихся войти в состав федерации, с другой - федерального парламента, а также издание соответствующего документа уполномоченным органом государственной власти. Такая прерогатива могла быть закреплена либо за федеральным парламентом (Конгресс США, Парламент Австралии, Парламент Индии), либо за главой государства (формально - за монархом Соединенного Королевства при расширении состава Канады).

Условия вхождения в союз на практике могли формулироваться как федеральным центром (Индия), так и самими территориальными образованиями, выразившими намерение войти в состав союза (Канада). При этом в первом случае предъявляемые требования были, как правило, идентичны для всех потенциальных субъектов федерации, в последнем - сравнительно различны, так как обусловливались интересами конкретного территориального образования в контексте конкретных исторически сложившихся внешнеполитических, внутриполитических, экономических и социальных условий. Так, например, приказ о вхождении в состав Канады Острова Принца Эдуарда ${ }^{21}$ содержал норму о возложении на федеральный центр обязанностей по обеспечению транспортного и почтового пароходного сообщения с островной провинцией и погашением ее долгов.

Следовательно, в первом случае складывающаяся федерация приобретала в большей степени симметричный характер, во втором - наоборот, скорее вела к

\footnotetext{
20 Ч. 4 ст. 5 Конституции Королевства Бельгия 1994 г.

${ }^{21}$ Приказ о вхождении в состав Канады Острова Принца Эдуарда [Electronic resource] // URL : http:/www.solon.org/Constitutions/ Canada/English/peitu.html
}

асимметрии. Действительно, если сравнивать условия и процедуру вхождения новых субъектов в состав федерации, например, в Канаде и Соединенных Штатах, то следует заметить, что Акт о Британской Северной Америке, в отличие от Северо-Западного Ордонанса ${ }^{22}$, не содержал формально равных требований к будущему субъекту федерации: условия присоединения в каждом конкретном случае вырабатывались индивидуально в ходе переговоров с учетом многих особенностей двусторонних и даже трехсторонних (учитывая интересы метрополии) отношений.

Северо-Западный Ордонанс 1787 г. регламентировал образование новых штатов на землях к северо-западу от реки Огайо, входивших в состав Соединенных Штатов и предусматривал, что новые штаты станут пользоваться теми же правами, что и старые: там будут приняты свои конституции, сформированы двухпалатные законодательные собрания, учрежден суд присяжных и т. д. Вместе с тем, как отмечает В. И. Терехов, посредством условий Ордонанса «создавались не только правовые условия для пространственного роста федерации, но и обеспечивалась довольно высокая степень однородности политической системы элементов, образующих федерацию» ${ }^{23}$.

Пожалуй, самый безапелляционный характер относительно закрепления прерогативы изменения состава и территории федерации имела Конституция Индии: федеральный Парламент посредством принятия закона вправе образовывать новые штаты (путем разделения, объединения, присоединения любых штатов и их частей), изменять их территорию (увеличивая или уменьшая ее), изменять границы и названия штатов ${ }^{24}$.

На практике расширение территории и субъектного состава в различных федерациях мира осуществлялось самыми разнообразными способами, в том числе не предусмотренными конституцией. Исследуя историю расширения территории Соединенных Штатов Америки, Я. М. Бельсон и К. Е. Ливанцев указывали на такие способы, как завоевание и покупка ${ }^{25}$ : у Испании в 1819 г. американцами была отвоевана

\footnotetext{
${ }^{22}$ An Ordinance for the government of the Territory of the United States northwest of the River Ohio [Electronic resource] // URL : http://avalon.law.yale.edu/18th_century/nworder.asp (12.02.2014).

${ }^{23}$ Терехов В. И. Американский федерализм: образец государственного устройства или предмет критического анализа? / Федерализм: теория и история развития (сравнительно-правовой анализ) / отв. ред. М. Н. Марченко. М: Юрист, 2000. С. 43.

${ }^{24}$ П. 3 Ст. 1 Конституции Республики Индия.

${ }^{25}$ Бельсон Я. М., Ливанцев К. Е. История государства и права США. Л. : Изд-во Лен. ун-та, 1987. С. 90.
} 
Флорида; у Мексики аннексированы и отвоеваны территории Калифорнии и Колорадо, частично - территория Аризоны, Нью-Мексики и Техаса. Луизиана, Аляска, Алеутские и Виргинские острова, южная часть штатов Нью-Мексика и Аризона были куплены соответственно у Франции, России и Мексики.

Исследователь истории Канады С. Ю. Данилов также отмечает, что «в 1870 г. канадское правительство приобрело за небольшую сумму у старинной купеческой корпорации - Компании Гудзонова залива - малонаселенные Северо-Западные территории» ${ }^{26}$.

Таким образом, фактически федерация может использовать любые приемлемые для нее способы расширения как своих границ, так и состава федерации.

Следующая проблема - как определить границы между субъектами федерации? Она становится особо острой при федерализации «сверху», когда приходится делить на части территорию, которая когда-либо была единой. Т. Фрейсер, исследуя реализацию идеи федерализма в Индии, отмечал, что «ее штаты основаны на больших по размеру провинциях Британской Индии и восходят к частям империи Моголов» ${ }^{27}$. В бывших испанских колониях отдельные субъекты федераций также формировались на базе административно-территориального деления, установленного еще испанской властью. Следовательно, при определении изначальных границ и размера субъектов федерации в большинстве случаев учитывались исторически сложившиеся экономические и культурные связи, а также политическое прошлое отдельных территорий.

Кроме того, как справедливо указывает C. Валентей, при определении границ субъекта федерации «то обстоятельство, что федерацию создают государственный образования, требует, чтобы полноправным субъектом федерации признавался лишь тот субъект, который способен реализовать принцип экономической самодостаточности. Реальная федерация возникает только тогда, когда объединяются и получают равные права экономически самодостаточные субъекты. Именно это обеспечивает их последующую политическую и правовую равностатусность, а не наоборот» ${ }^{28}$. То есть в первую очередь нужно учитывать экономические факторы, которые позднее будут существенно влиять на политическую и социальную стабильность внутри федерации.

Таким образом, на основе анализа текстов конституций, впервые закреплявших федеративное устройство конкретного государства, можно сделать вывод, что наиболее стабильными стали те федерации, конституции которых изначально содержали полный перечень фактически вошедших в состав субъектов федерации, предусматривали условия для вхождения новых субъектов, закрепляли порядок пересмотра границ между субъектами федерации с учетом их мнения.

Кроме того, следует признать положительным опыт тех федераций, формирование территории которых осуществлялось, исходя из принципа экономической самодостаточности каждого субъекта федерации, где в основу формирования территории был положен территориальный, а не национальный принцип, и где с учетом географических и климатических условий часть территории федерации оставалась под прямым управлением федеральных властей, не переходя в состав территории какого-либо субъекта федерации, и не создавая асимметрии его правового статуса.

\section{Библиография:}

1. Акт о Британской Северной Америке 1867 г. / Конституции государств американского континента: в 2 т. Т. 2. Перевод под ред. проф. Г. С. Гурвича. М.: Изд-во иностранной лит-ры, 1959. С. 13-50.

2. Временная Конституция Танзании 1965 г. // Конституции государств Африки. Т. 2. М., 1966. С. 494-548.

3. Конституционный Акт Содружества Австралия от 9 июля 1900 г. / Конституции государств Юго-Восточной Азии и Тихого океана. Перевод под ред. 3. И. Луковниковой. М. : Изд-во иностранной лит-ры, 1960. С. 16-52.

4. Конституция Аргентинской нации от 1 мая 1853 г. / Конституции государств американского континента: в 2 т. T. 1. Перевод под ред. проф. Г. С. Гурвича. М. : Изд-во иностр. лит-ры, 1957. С. 12-37.

5. Конституция Королевства Бельгия 1994 г. / Конституции государств Европы: В 3 т. Т 1 / Под общ. ред. Л. А. Окунькова. М.: Изд-во НОРМА, 2001. С. 341-380

6. Конституция Малайской Федерации / Конституции государств Юго-Восточной Азии Тихого океана. М., 1960. C. 245-396.

\footnotetext{
26 Данилов С. Ю. К «кооперативному» федерализму (конец 19-середина 20 вв.) / Федерализм: Теория и история развития / отв. ред. М. Н. Марченко. М. : Юристъ, 2000. С.85-92. С. 85

${ }^{27}$ Fraser T. G. Federal solutions to the problems of Indian unity, 1930-1946 // A Constitution for Europe. A comparative study of Federal Constitutions and Plans for the United States of Europe. / Ed. P. King and A. Bosco. London, Lothian foundation press, 1991. P. 267-283. P. 279.
}

\footnotetext{
${ }^{28}$ Валентей С. Д. Экономические проблемы становления российского федерализма: [Электронный ресурс] // URL : http://www. budgetrf.ru/Publications /Magazines/Federalizm/1999/Federalism11999Valentey/Federalism1-1999Valentey 000. htm (12.12.2013).
} 
7. Конституция Папуа Новой Гвинеи 1975 г. [Electronic resource] // URL : http://www.paclii. org/pg/legis/consol_act/cotisopng534 (17.02.2014).

8. Конституция Российской Федерации. М.: Юридическая литература, 1993.

9. Конституция (Основной закон) РСФСР от 10 июля 1918 г. / Собрание узаконений РСФСР. 1918. № 51. Ст. 582.

10. Конституция Соединенных Штатов Америки 1787 г. / Конституции и законодательные акты буржуазных государств XVII-XIX вв.: Сборник документов / Под ред. проф. П. Н. Галанзы. М.: Гос. изд-во юрид. лит., 1957. С. 178-190.

11. Конституция Федеративных Штатов Микронезии 1979 г. [Electronic resource] // URL : http://www.paclii.org/fm/legis/ consol_act/cotfsom468 (13.05.2014).

12. Приказ о вхождении в состав Канады Острова Принца Эдуарда [Electronic resource] // URL : http://www.solon.org/ Constitutions/Canada/English/peitu.html

13. Федеральная Конституция Швейцарии 1848 г. / пер. с нем. С. А. Соломоновой // Правоведение. 2005. № 3. С. 167-183.

14. An Ordinance for the government of the Territory of the United States northwest of the River Ohio [Electronic resource] // URL : http://avalon.law.yale.edu/18th_century/nworder.asp (12.02.2014).

15. Ахтамзян А. А. История германского федерализма от «союза князей» до конституционной федерации / Федерализм: Теория и история развития: сб. ст. / Отв. ред. М. Н. Марченко. - М.: Юристъ, 2000. С. 116-127.

16. Бельсон Я. М., Ливанцев К. Е. История государства и права США. Л.: Изд-во Лен. ун-та, 1987.

17. Валентей С. Д. Экономические проблемы становления российского федерализма: [Электронный ресурc] // URL : http://www.budgetrf.ru/Publications /Magazines/Federalizm/1999/Federalism1-1999Valentey/Federalism1-1999Valentey 000. htm (12.12.2013).

18. Данилов С. Ю. К «кооперативному» федерализму (конец 19-середина 20 вв.) / Федерализм: Теория и история развития / отв. ред. М. Н. Марченко. М.: Юристъ, 2000. С.85-92.

19. Терехов В. И. Американский федерализм: образец государственного устройства или предмет критического анализа? / Федерализм: теория и история развития (сравнительно-правовой анализ) / отв. ред. М. Н. Марченко. М: Юрист, 2000.

20. Чиркин В. Е. Современное федеративное государство. М., 1997.

21. Fraser T. G. Federal solutions to the problems of Indian unity, 1930-1946 // A Constitution for Europe. A comparative study of Federal Constitutions and Plans for the United States of Europe. / Ed. P. King and A. Bosco. London, Lothian foundation press, 1991. P. 267-283

22. А.Н. Чертков О составе территории Российской Федерации // Журнал зарубежного законодательства и сравнительного правоведения. $-2011 .-6 .-$ С. $38-44$.

23. В. Г. Вишняков Проблемы укрепления территориальных основ Российской Федерации // Политика и Общество. 2012. - 5. - C. $21-28$.

\section{References (transliterated):}

1. Akhtamzyan A. A. Istoriya germanskogo federalizma ot «soyuza knyazei» do konstitutsionnoi federatsii / Federalizm: Teoriya i istoriya razvitiya: sb. st. / Otv. red. M. N. Marchenko. - M.: Yurist", 2000. S. 116-127.

2. Bel'son Ya. M., Livantsev K. E. Istoriya gosudarstva i prava SShA. L.: Izd-vo Len. un-ta, 1987.

3. Valentei S. D. Ekonomicheskie problemy stanovleniya rossiiskogo federalizma: [Elektronnyi resurs] // URL : http://www.budgetrf.ru/Publications /Magazines/Federalizm/1999/Federalism1-1999Valentey/Federalism1-1999Valentey 000. htm (12.12.2013).

4. Danilov S. Yu. K «kooperativnomu» federalizmu (konets 19-seredina 20 vv.) / Federalizm: Teoriya i istoriya razvitiya / otv. red. M. N. Marchenko. M.: Yurist”, 2000. S.85-92.

5. Terekhov V. I. Amerikanskii federalizm: obrazets gosudarstvennogo ustroistva ili predmet kriticheskogo analiza? / Federalizm: teoriya i istoriya razvitiya (sravnitel'no-pravovoi analiz) / otv. red. M. N. Marchenko. M: Yurist, 2000.

6. $\quad$ Chirkin V. E. Sovremennoe federativnoe gosudarstvo. M., 1997.

7. Fraser T. G. Federal solutions to the problems of Indian unity, 1930-1946 // A Constitution for Europe. A comparative study of Federal Constitutions and Plans for the United States of Europe. / Ed. P. King and A. Bosco. London, Lothian foundation press, 1991. P. 267-283

8. A.N. Chertkov O sostave territorii Rossiiskoi Federatsii // Zhurnal zarubezhnogo zakonodatel'stva i sravnitel'nogo pravovedeniya. - 2011. - 6. - C. $38-44$.

9. V. G. Vishnyakov Problemy ukrepleniya territorial'nykh osnov Rossiiskoi Federatsii // Politika i Obshchestvo. - 2012. 5. - C. $21-28$. 